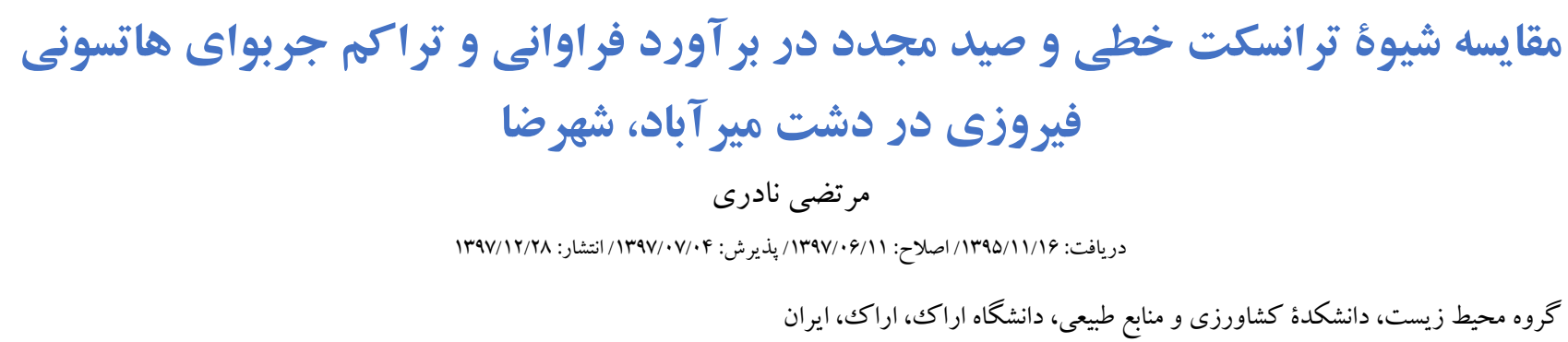
مسئول مكاتبات: m-naderi@araku.ac.ir

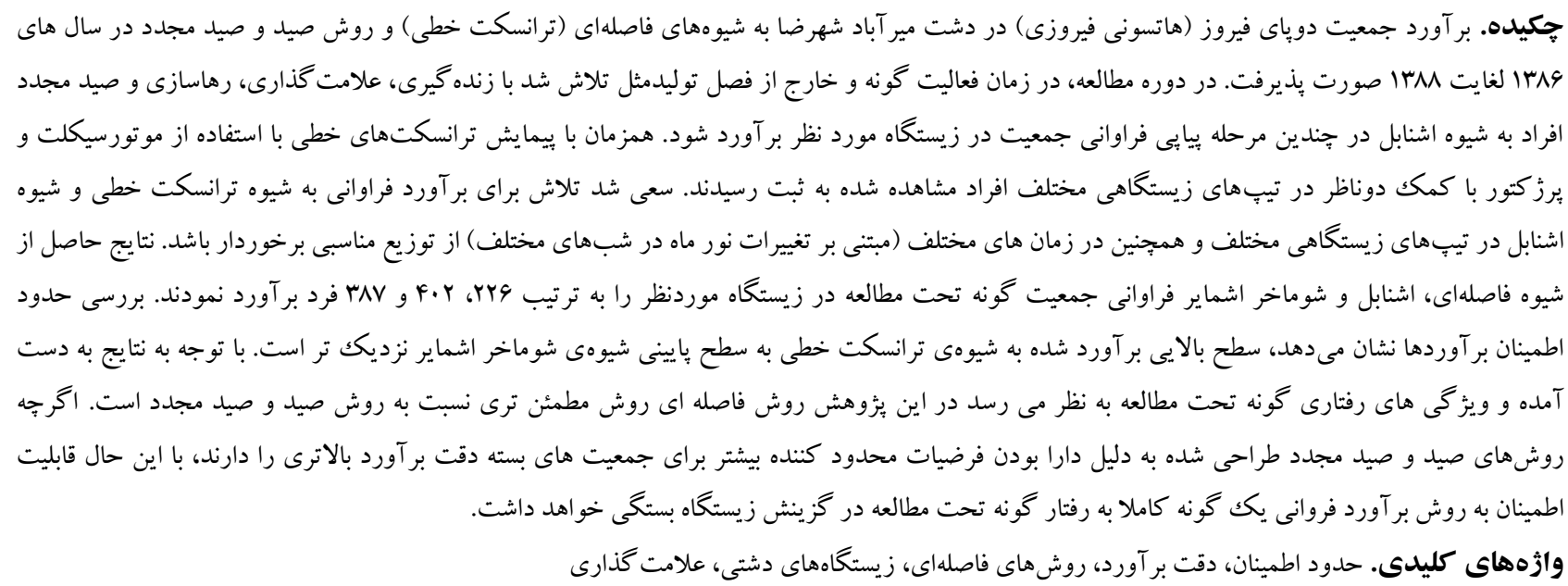

\title{
A comparison of linear transect and capture recapture methods results in Iranian Jerboa population density and abundance estimation in Mirabad plains, Shahreza Morteza Naderi
}

Received 04.02.2017/ Revised 02.09.2018/ Accepted 26.09.2018/ Published 19.03.2019

Department of Environmental Sciences, Faculty of Agriculture and Natural Sciences, Arak University, Arak, Iran Correspondent author: m-naderi@araku.ac.ir

\begin{abstract}
During a period from spring 2008 till fall 2010, Iranian Jerboa population abundance was estimated using distance (linear transect) and capture-recapture methods in the Mirabad plains near Shahreza city in Isfahan Province. In the study period, during the active time of the species except reproduction time, we tried to live-trap, mark, release and recapture individuals based on Schnabel method on different sampling occasions. Simultaneously, we also traversed line transects using motorcycle and spot-light by two observers in different habitat types. We tried to get uniform trapping nights in different lunar nights and different habitat types. The population abundance, using Schnabel and distance methods was estimated to be 226 and 402 individuals, respectively. With regard to the obtained results and species behavior, it seems that distance method yields more precise confidence limits of the estimation compared with capture-recapture method. However, capture-recapture method yields more precise estimates for closed populations because of its more limiting assumptions, but the confidence reliability of abundance estimation of a species depends on the species and its habitat selection behavior completely.
\end{abstract}

Keywords. confidence limits, distance methods, estimation precision, marking, plain habitats 
وقتى بتوان از يكك جمعيت خندين فرد رازنده گيرى كرد بدون آن كه آسيبى به آنها برسد و گونه تحت مطالعه كمياب نباشد، استفاده از

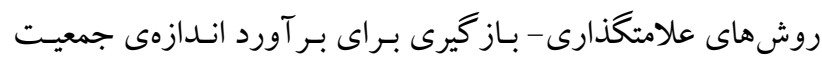

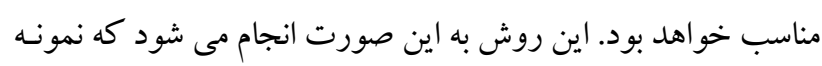

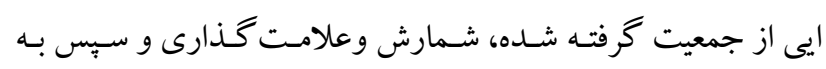

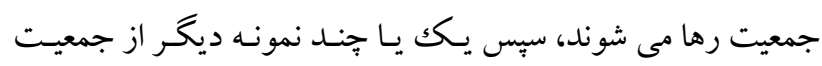

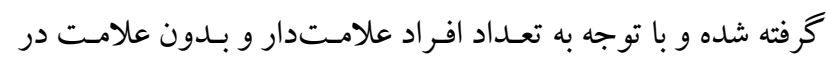

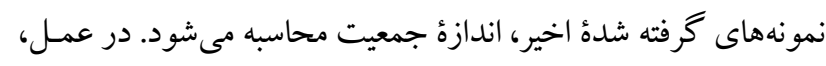

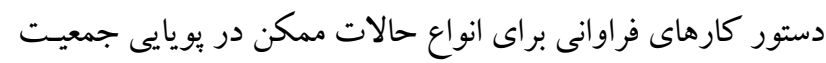

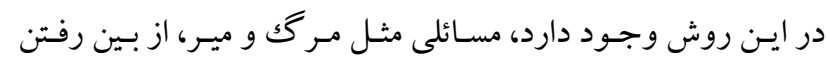

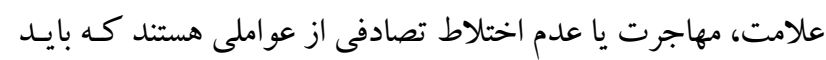

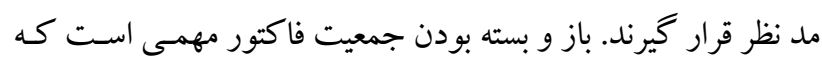

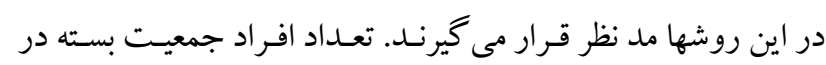

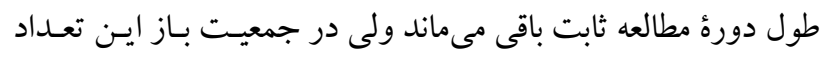

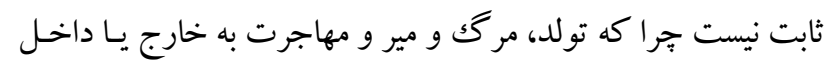

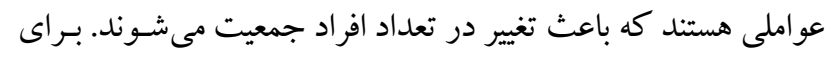

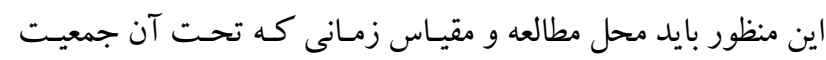

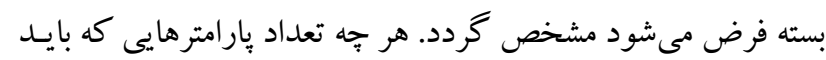

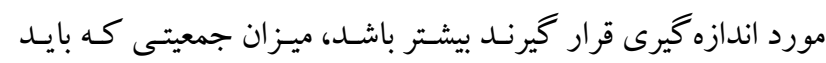
كرفته شده و علامت كذارى شود نيز بيشتر است. براى بر آورد انـازئ

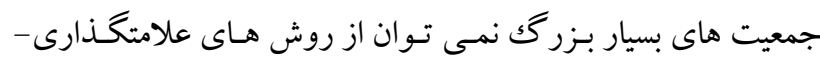

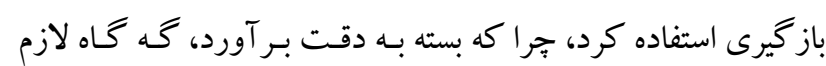

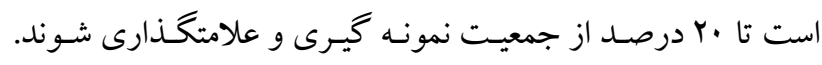

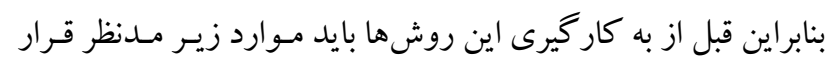

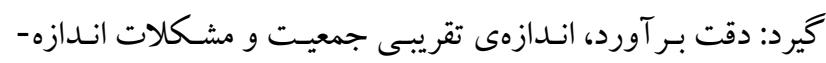

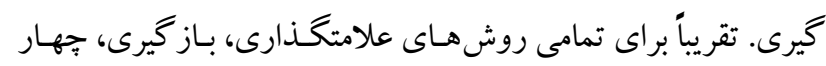
ييش فرض مهم وجود دارد (Krebs, 1999):

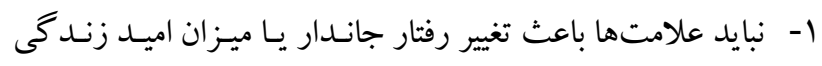

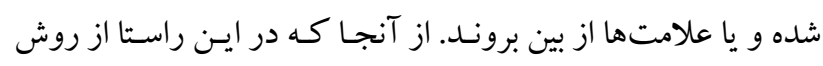

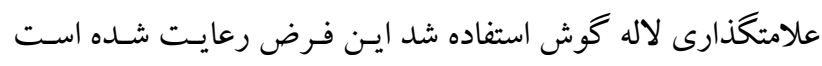

.(Shenbrot, 1991)

r- وقتى افراد علامتدار به جمعيت بر گردانده مىشوند كاملاً با آن

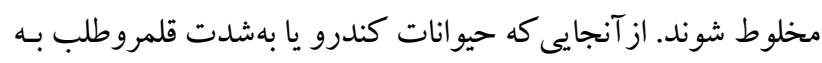

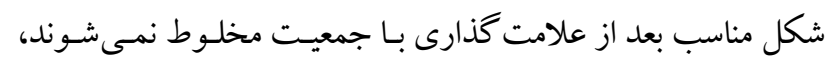

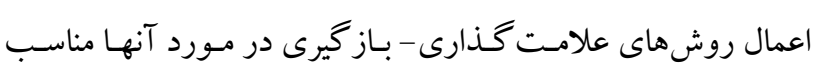

مقام

بر آورد فراوانى بِّتانداران كوجّك تاكنون توسط محققين بسيارى

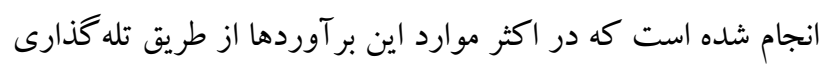

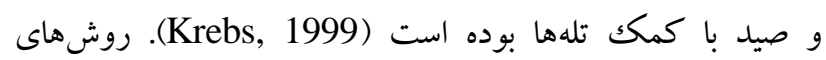
فاصلهاى از جمله روشهايى هستند كه در استفاده از آنها نيازى به به روته صيد جاندار نبوده و مشاهدهى آن كفايت خواهد كرد. روش روش تعيين

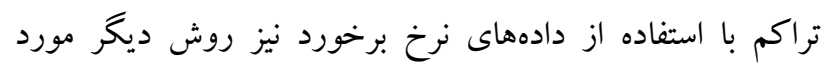

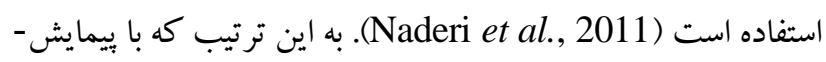

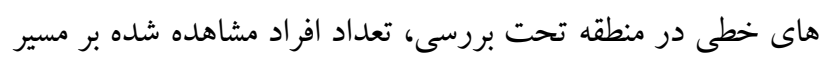

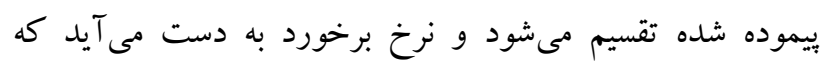

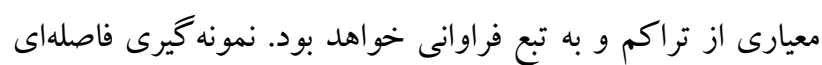

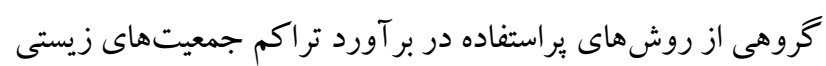

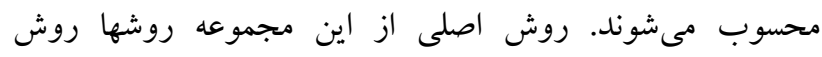

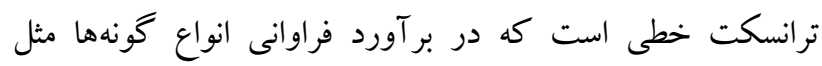

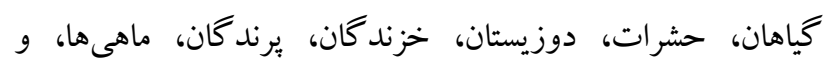

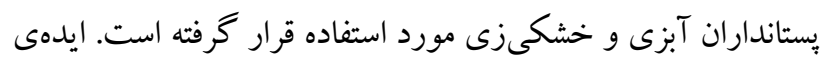
اصلى در اين روش بسيار ساده و قابل دركك است به اين صورت كورد ناظر در طول يكك سرى خطوط اقدام به ثبت فاصلهى شى يا جاندار از خط حركت خود مىنمايد. البته لزوما تمامى اشيا يا جانداران

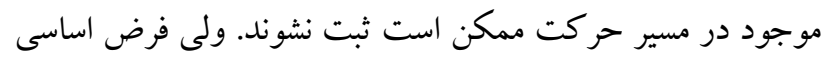

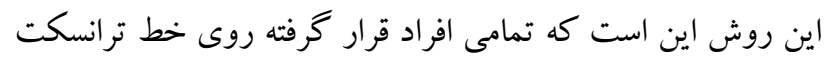

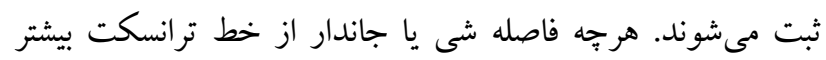

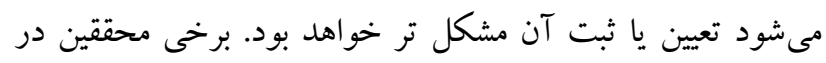

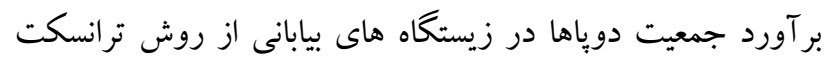

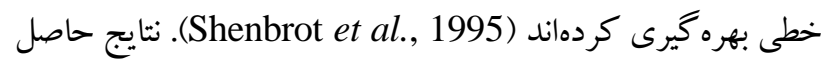

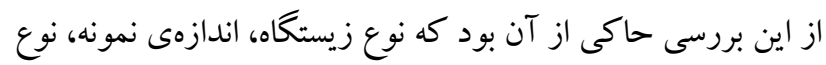

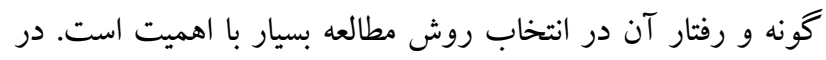

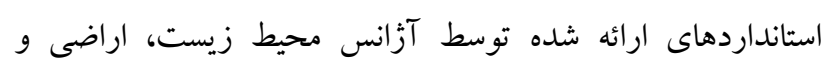

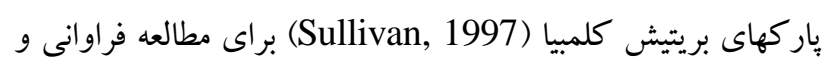

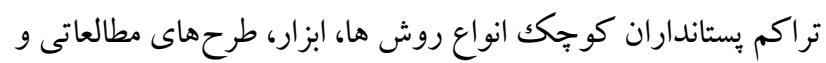

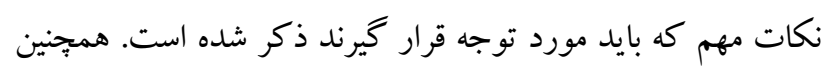

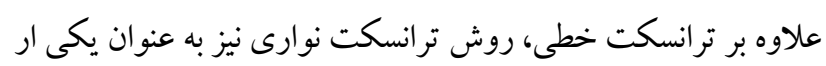

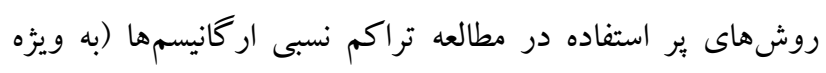
ار كانيسمهايى با تحر ك كم) و همجنين اشيا است (Krebs, 1999). 
در اين رابطه a تعـداد افر اد جديـدى اسـت كـه در مرحلـهى دوم

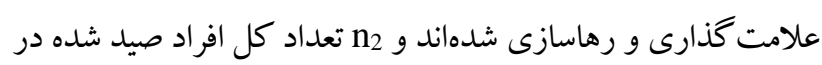
مرحلهى دوم و r تعداد افراد علامتدارى كه مجـدداً صسيد شـدهاند. انديس اول نشاندهندهى مرحله صيد وانديس دوم نمايانكر مرحلـهى

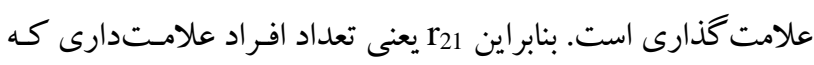
در روز اول علامت گذارى شــه و در روز دوم صسيد شـدهانـد و تعداد افرادى كـه در روز اول علامست گَذارى شـده و در روز سـوم صيد شدهاند. مسلماً تعداد علامتهـا مسـاله اى مهـم اسـت و بنـابراين ممكن است همان افراد كه در r31 ظاهر مسى شـوند در r32 نيـز وجـود داشته باشند.

روش اشنابل: روش اشنابل شكل تغيير يافته روش بيترسـون اسـت. به اين صورت كه جنـــين دوروى نمونسه گيرى و علامتخـذارى افـراد انجام مى يذيرد. افرادى كه صيد مىشـوند از نظر داشـتن يـا نداشـتن علامت تحت بررسى قرار مى گيرند و سبس علامتخذارى شده و رها مىشوند. در واقع در ايسن روش افر اد بـه دو دسـته تقسـيم مىشـوند داراى علامت و بـدون علامـت (رابطه ب). در ايسن رابطـه، N معـادل فراوانى، Ce Cعادل كل افراد صيد شده در نمونسه tو علامتدار درست قبل از زمان نمونه t و تعداد افر اد صيدشدهاى كه

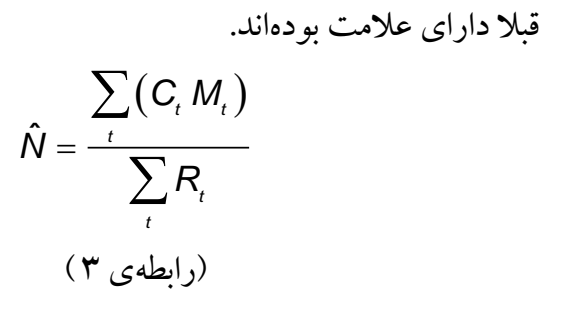

براى بر آورد واريانس و حدود اطمينان اين روش به ترتيب از روابط r و براستفاده مىشود. Standard Error of $\left(\frac{1}{\hat{N}}\right)=\sqrt{\frac{\text { Variance of }(1 / \hat{N})}{\sum\left(C_{t} M_{t}^{2}\right)}}$

$$
\begin{gathered}
\text { (f f رابطهى }) \\
\frac{1}{\hat{N}} \pm t_{\alpha} \text { S.E. } \\
(\text { (رابطهى })
\end{gathered}
$$

اين روش تمامى فرضهاى روش بيترسون را دربرمى گيرد مواردى مثل ثابت بودن جمعيت بدون افزايش يا كاهش، نمونه گيرى تصادفى

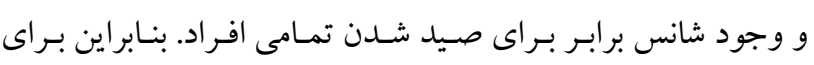
رعايت اين مفروضات دوره نمونه كيرى به قبل از وارد شدن زادگتان
نيست.احتمال به دام افتادن يـك حيـوان علامتـدار بـا احتمـال بـه دام افتادن هر عضو ديخر جمعيت برابر باشد. رعايت فرض (اصسيديذيرى برابر) اغلب كارى مشكل است و بايد در نظر داشـت كـه ايسن مسـأله

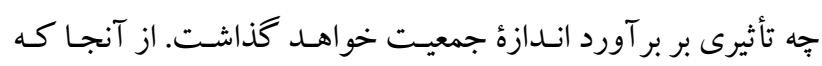

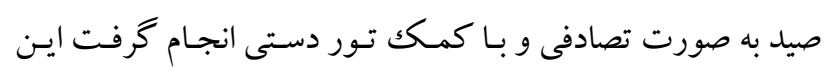
فرض نيز در مطالعه انجام شده رعايت شده است. نمونه گيرى بايد در

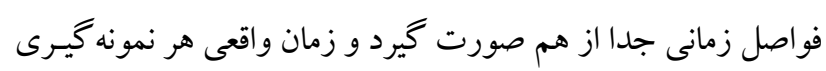
بايد در مقايسه با زمان كل، كم باشــ. بـا توجـه بـه ايسن كـه بـه طـور متوسط هر دو هفته يكبار و در هر بار به طور متوسط سه شـب نمونـه كيرى انجام شد اين فرض نيز رعايت شد. وقتى جمعيت بسـته باشـد، احتمال اسارت ثابت بوده و جهار فرض فـوق صـادق اسـت. در ايـن صورت اندازه كل جمعيت از شاخص ساده ايسى كـه توسط ليـنكلن (Lincoln, 1930)

$$
\hat{N}=\frac{a n}{r}(\text { (رابطهى) }
$$

در اين رابطه N م تعداد افراد جمعيت، a تعـداد كـل افراد علامـت دار در نمونسه اول، n تعـداد افراد در نمونسه دوم و r تعـاد كـل افـراد

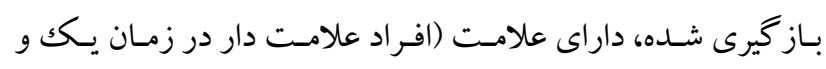
باز كيرى شده در زمان دو). وقتى حيو انات دو يا تعداد دفعات بيشترى

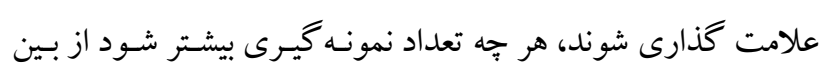
رفتن تعدادى از افراد علامت دار بين زمان رها سازى اول و زمانى كه

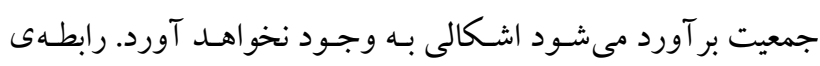

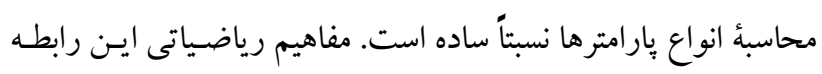
توسط بيلى (Baily, 1951) تشريح شـده و بيلى (Baily, 1952) و مكك لئود (MacLeod, 1958) آن را تعريـف كردهانـد. ايـن رابطه.

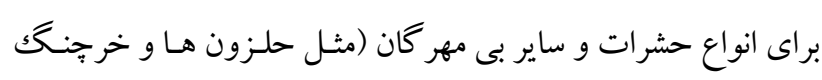
ها) مورد استفاده قرار كرفته است. فواصل زمانى بين نمونسه كيرى إهـا مى تواند به هر نحو ممكن اتفاق بيفتد، به شرطى كه به قدر كافى ايسن فواصل زمانى طولانى باشند كه به افراد علامت دار اجازه دهد كه بـهـ

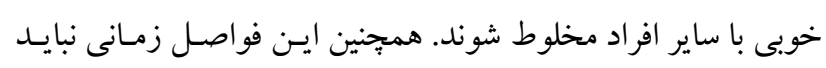

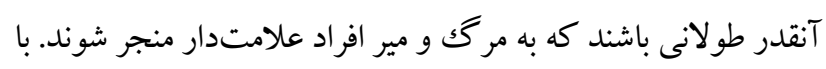

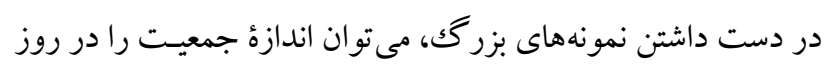
دوم بهصورت زير محاسبه كرد:

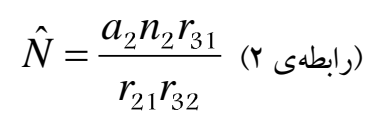




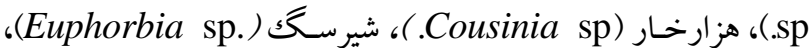
درمنه (Artemisia herba alba)، جارو (Scariola orientalis) اشاره كرد. در اين مطالعه با توجه به عدم وجود هيج لايه اطلاعاتى از منطقه، تيبـهاى گيـاهى منطقـه استخراج شـد. در ايسن منطقـه انـواع كونهاى گياهى خاص تيب اراضى بـت و شـور، مقعـر آبرفتى وبـا

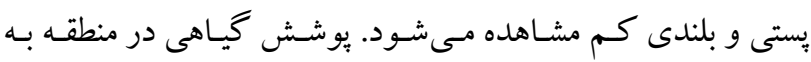

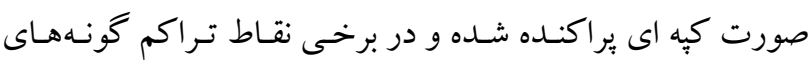

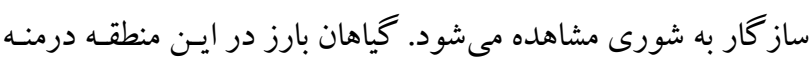
دشتى (Artemisia siberi Besser) و شور (Anabasis aphylla)

(L

كونه تحت مطالعه

در برخى از مطالعات انجام شده از دوياى فيروز به عنسوان گونه ایى

Darvish et al., ) مشتق شـده از دويـاى هاتسـون يـاد شـده اسـت 2008). شنبورت (Shenbrot, 1991) اين گونه را گونه اي همسان بـا دويـاى كوجـك (A. elater) دانسـته امـا برخـى (Synonym)

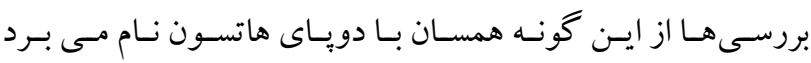

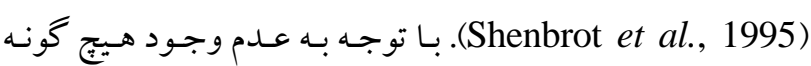
اطلاعـاتى در خصـوص ايـن گونسه، وضسعيت تاكسـونوميكك آن تـا آخرين بازنخرى انجام شده توسط (Holden \& Musser, 2005) بدون تغيير باقى ماند. اما با بررسى هاى صورت كرفته و ييشرفت هاى برد Allactaga F. Cuvier, ايجاد شده در طبقـه بنـدى جـس 1836 و بررسى نمونسهاى (Shenbrot, 1991; Colak et al., 1994) موجود دوياى هاتسون در موزمى تاريخ طبيعى واشنگتن (كه از ايران و ياكستان جمـع آورى شـده بودنـد) وضسعيت آرايهشـناختى دويـاى

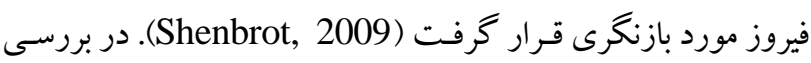
اخير اذعان شده است كه با توجه به دادهاى اكوجغر افيايى مسىتوان A. hotsoni ( دوياى فيروز رابه عنوان زير گ نهاى از دوياى هاتسون

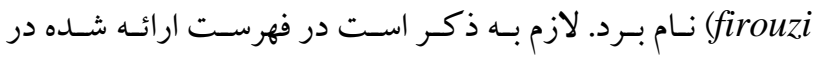
خصوص بِستانداران ايـران (Karami et al., 2008) ايـن گونـه بـا عنوان دوياى فيروز (Airouzi) (A) معرفى شده است.

\section{روشهاى بر آورد جمعيت}

در بر آورد تراكم وفراوانى (با بهـره كيـرى از روش ترانسـكتهاى خطى)، توزيـع فراوانسى فواصـل عمـود بـر خـط ترانسـكت از محـل مشاهدهى دوياى فيروز جهت محاسبه تابع f(x) مـورد اسـتفاده قـرار كرفت. اين تابع كاهش ميزان برخورد با افراد كونه تحت مطالعه رابـا بـابـ
جديد به جمعيت (Naderi et al., 2009) محدود كشـت همجنـين

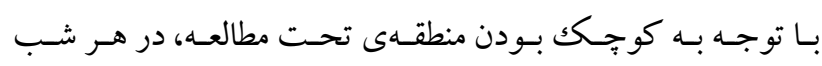
نمونه كيرى، كل منطقه با كمكك موتورسـيكلت تحـت بوشـش قرار داده مىشد. با توجه به تراكم يايين گونه تحت مطالعه امكان استفاده از روش بيترسون وجود نداشت و در طى جنديد بـار نمونـهـ گيرى بـر

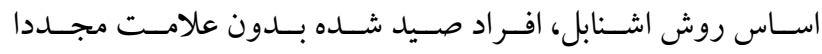

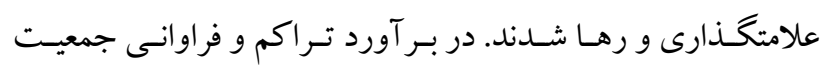
جوند كان روش هاى متفاوتى استفاده مى شود. بـهـ عنـوان مثـال بـراى

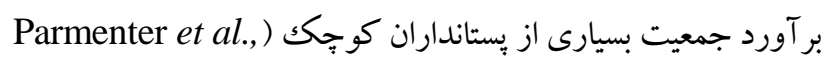
Wilson et al., ) (Rattus rattus) بـه عنـوان مثـال رت 2017) روش صيد و صيد مجدد (روش بيترسن) مورد اسـتفاده قرار كرفته است. در برخى مطالعات نيز از روش هاى فاصله اى (بـه ويـرّه تر انسكت خطى و نوارى) و يـا روش هـاى برداشـى (حسذفى) بـراى

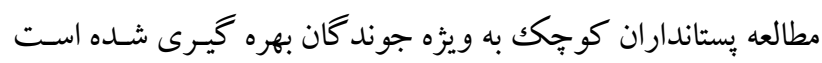

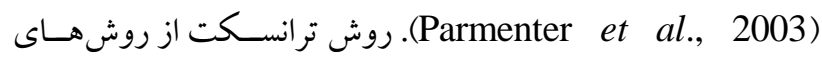
B.C. Ministry of ) بر كاربرد در ايسن قبيل مطالعـات بـوده اسـت براى صيد گونهاى تحت مطالعه ار روش (Environment, 1998 تله كذارى و استفاده از تلههاى قفسى مشـبك، آشـيانه هـاى جعبـهاى

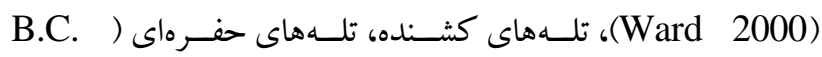
Ministry of Environment, 1998 دستى بهره گيرى شده است (Parmenter et al., 2003).

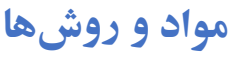
منطقة تحت مطالعه

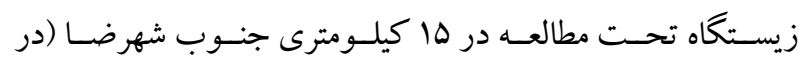

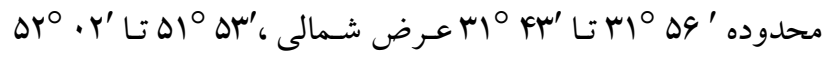
عرض شرقى)، و در محدوده روستاهاى وشاره و مير آباد قـرار گرفتـه و تا محدوده مرزى استان اصفهان و فارس امتداد مسى يابـد. زيستـاه تحت مطالعه عمدتا دشتى و بافت خاكك عمـدتاً از سـه گحروه شـنى رسى -لومى، رسى - لومى و شنى - لـومى تشـكيل شـده اسـت. ميززان كربنات كلسيم در خاكى نسبتاً بالا است. يوشش كياهى منطقه: در منطقه تحت مطالعه دو تيب گياهى غالب، تيستب آناباسـيس Anabasis aphyllaو تيسب درمنـه Artemisia siberi مى توان به اسفند (L. Peganum harmala)، جرخه ( Launaea) 


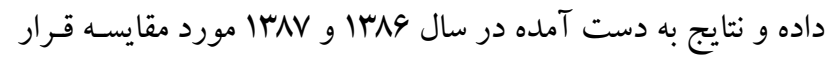
كيرد. تكرار اين روش در سال دوم در بررسى قابل اعتماد بودن نتايج

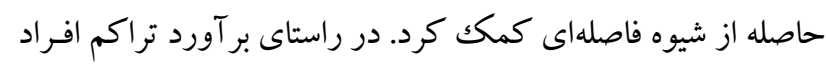

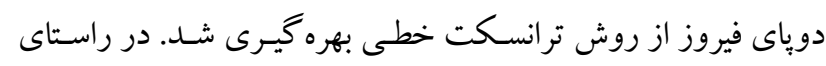

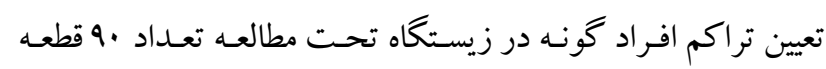

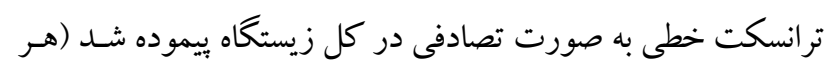

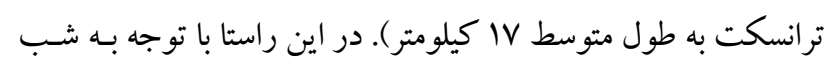

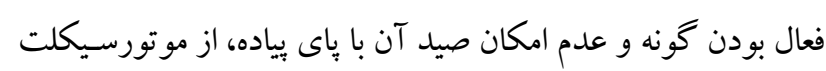

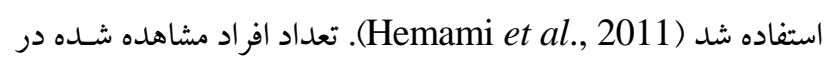
واحد مسافت بيموده شده نرخ برخورد را ارائه مى نمايد كه به عنوان

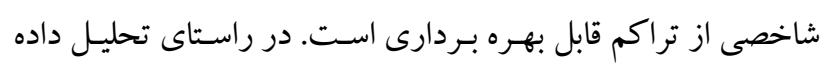

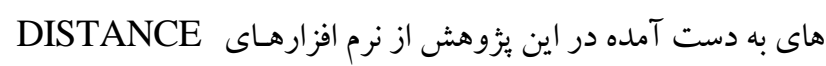

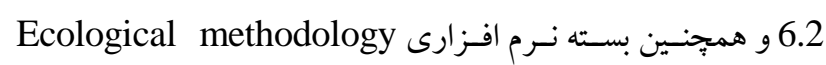

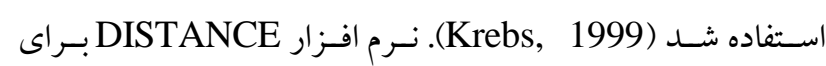

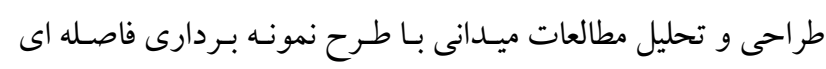

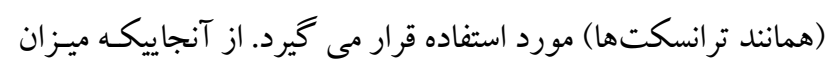

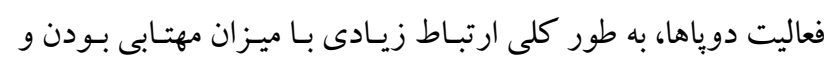

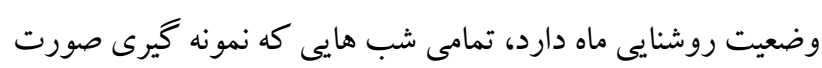

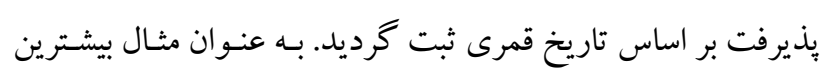

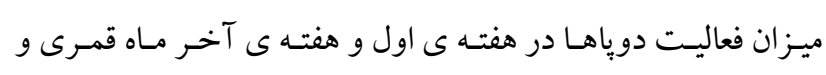

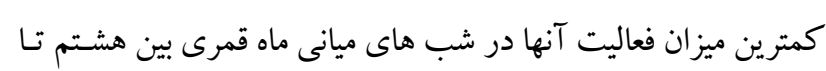

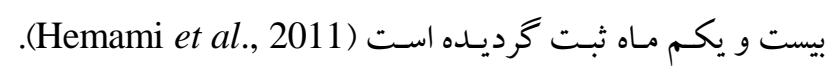
هدف از ثبت تاريخ قمرى در نمونه گيرى، اطمينان از توزيع متعـادل

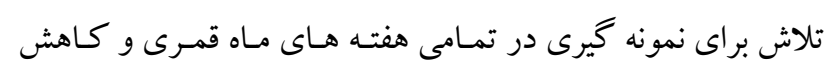

$$
\text { اريبى در نتايج است. }
$$

\section{نتائج و بحث}

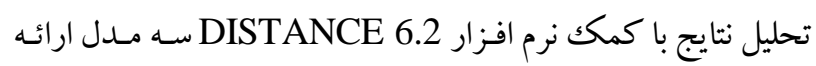
كرد كه بر اسـاس معيار حسداقل AIC (Akaike's Information بهترين مدل انتخاب شد. سه Criterion)

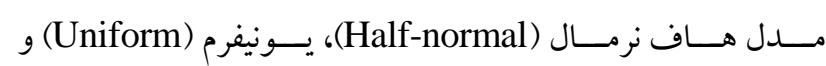
هازاردريت (Hazard rate) در تحليل ها مورد استفاده قرار گرفتنـد.

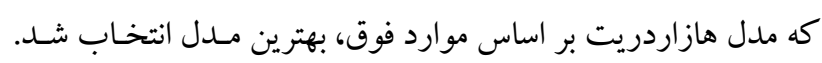

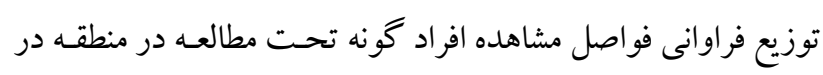

دور شـدن از محسور ترانسـكت بـه مــل تبــــل مىنمايســ. عـلاوه بـر

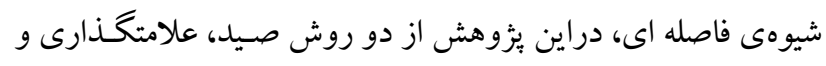

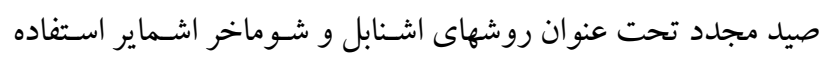
شد. در روش اشنابل برخلاف روش بيترسون كه از دو مرحلـه نمونسه

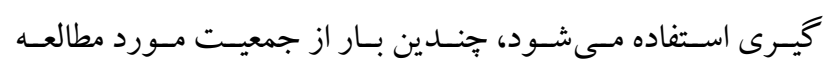

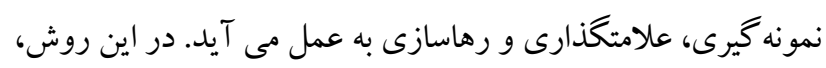

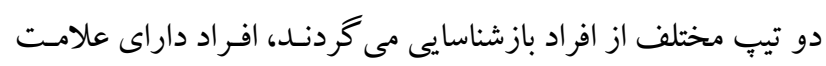

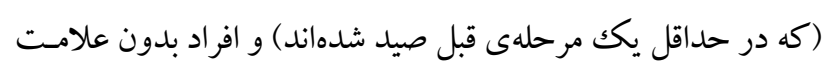

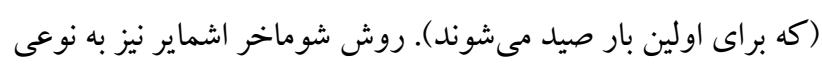

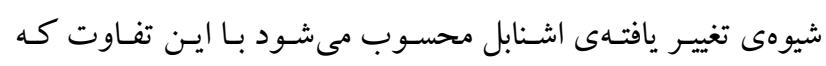

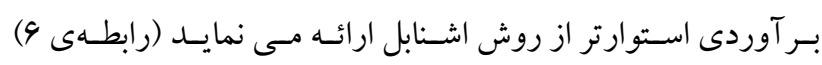

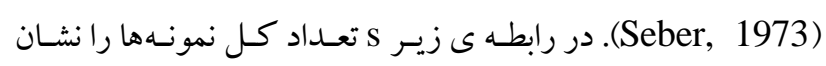

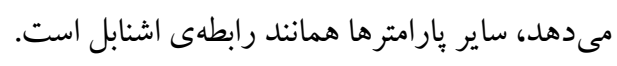

$$
\hat{N}=\frac{\sum_{t=1}^{s}\left(C_{t} M_{t}^{2}\right)}{\sum_{t=1}^{s}\left(R_{t} M_{t}\right)}
$$

(رابطهى (4) (1)

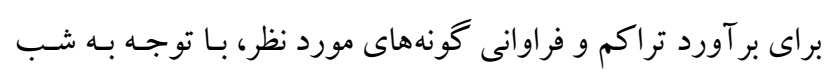

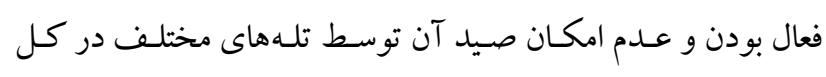

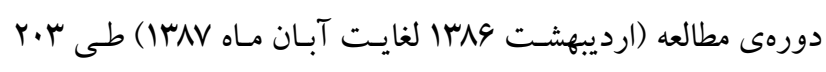

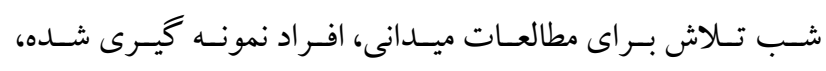

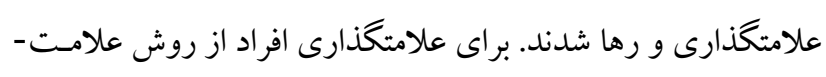

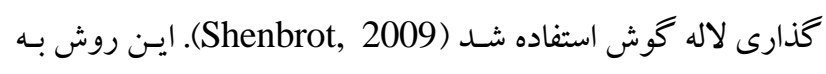

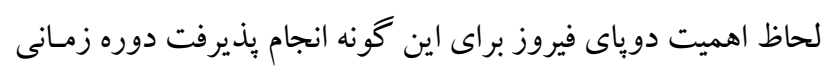

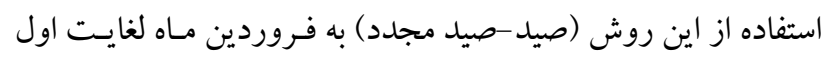

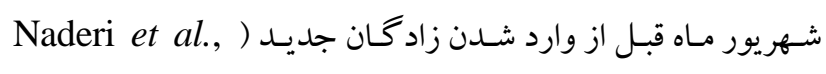

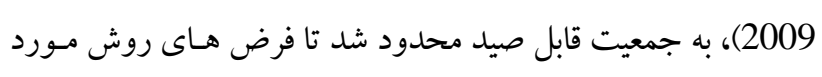

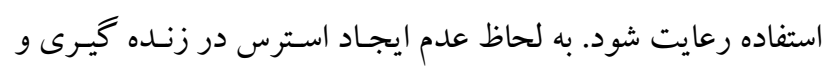

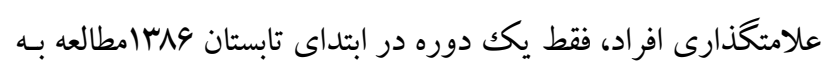

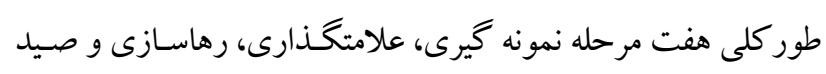

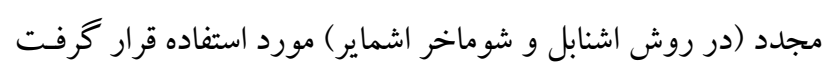

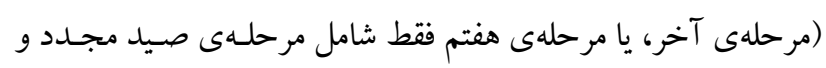

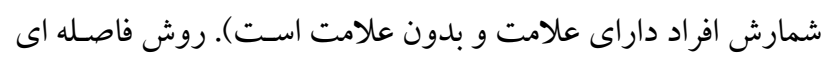

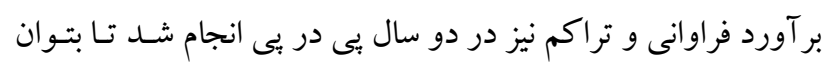


جدول ا- نتايج حاصل از تحليلهاى انجام شده توسط نرمافزار DISTANCE.

Table 1. Results of DISTANCE analysis.

\begin{tabular}{|c|c|c|c|c|c|c|c|c|c|c|}
\hline نرخ برخورد (فرد در & احتمال تعيين يا & عرض موثر & \multicolumn{3}{|c|}{ نيكويى برازش } & مدل برازش شده & ضريب تغييرات & تراكم در كيلومتر مربع & تعداد افراد (n) & زيستكاه \\
\hline \multirow{2}{*}{.191} & \multirow{2}{*}{$\cdot / r \Lambda$} & \multirow{2}{*}{$0 / 99$} & $P$ & df & ${ }^{r} \chi$ & \multirow{2}{*}{$\begin{array}{c}\text { Hazard- } \\
\text { Rate/Cosine }\end{array}$} & \multirow{2}{*}{$19 / 1 \mathrm{Y}$} & $\mid r / r q$ & TYG & \multirow{2}{*}{ كل منطقه } \\
\hline & & & .1 .9 & f & .190 & & & $(\Lambda / A r-19 / M r)$ & $(19 r-r \cdot 1)$ & \\
\hline
\end{tabular}

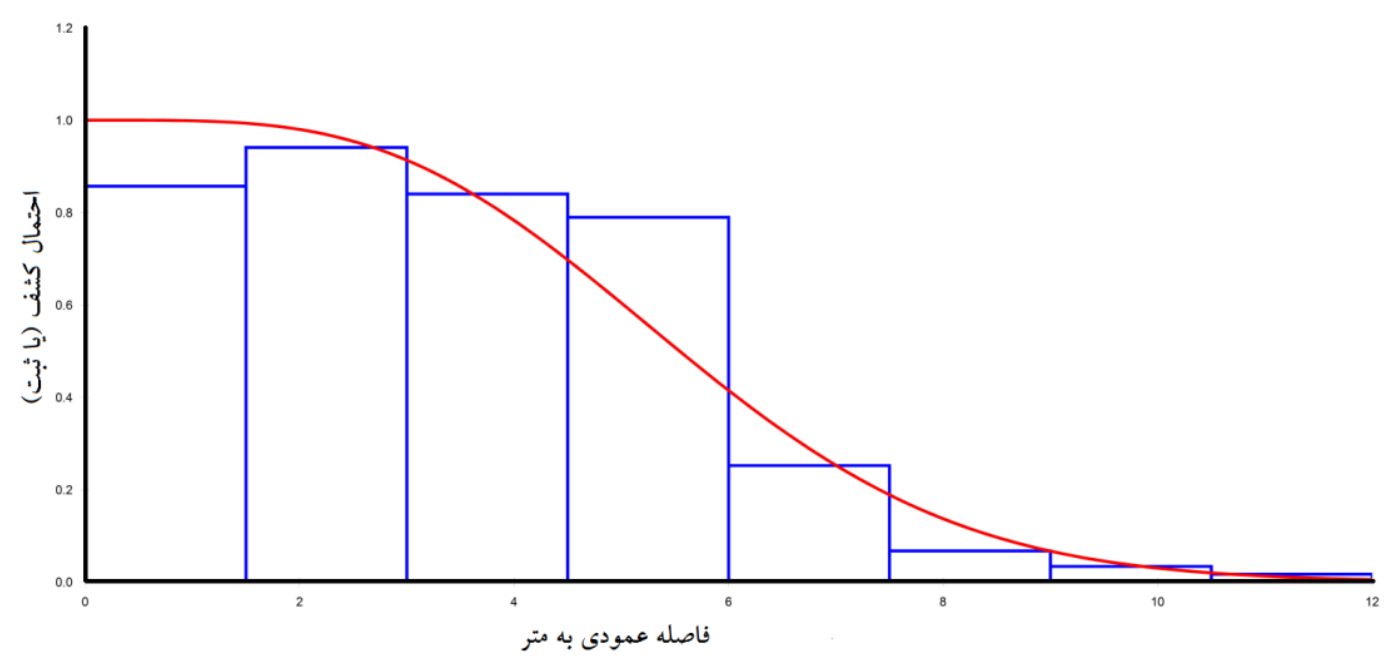

شكل ا- توزيع فراوانى فواصل كشف افراد گونه تحت مطالعه در هر يك از تيبهاى زيستخاهى.

Fig. 1. Individuals' detection frequency distribution in each habitat type.

جدول r - دادههاى مربوط به روش اشنابل در بر آورد فراوانى و تراكم افراد گونه تحت مطالعه.

Table 2. Data related to the Schnabel method in population density and abundance estimation.

\begin{tabular}{|c|c|c|c|c|}
\hline 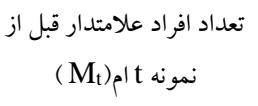 & 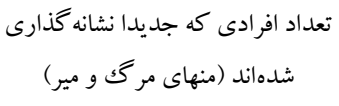 & 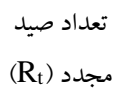 & $\begin{array}{c}\text { تعداد صيد } \\
\left(C_{t}\right)\end{array}$ & نمونه كرى احل \\
\hline . & r & . & r & 1 \\
\hline r & 19 & 1 & IV & $r$ \\
\hline ma & re & $r$ & ra & $r$ \\
\hline$V \Delta$ & FA & $\Lambda$ & $\Delta \varphi$ & $F$ \\
\hline Irr & rI & 11 & rr & $\Delta$ \\
\hline IFF & 19 & 1. & rq & 9 \\
\hline 19. & - & 19 & rV & V \\
\hline- & 19. & $\mathrm{Fq}$ & r. & مجموع \\
\hline
\end{tabular}

جدول ب- بر آورد جمعيت به روشهاى شوماخر و اشنابل، ترانسكت خطى و حدود اطمينان هر كدام از روش ها و حدود اطمينان بر آورد.

Table 3. Population estimation using Schumacher, Schnabel and line transect methods as well as their confidence limits.

\begin{tabular}{|c|c|c|}
\hline بر آورد شيوهى فاصلهاى & بر آورد اشنابل & بر آورد شوماخر اشماير از جمعيت \\
\hline TYG (1GY-r.1) & $F \cdot Y(r) \cdot-\Delta F V)$ & MAV (TFY-FFD) \\
\hline
\end{tabular}


فراوانى بر آورد شده توسط روش ترانسكت خطى حاكى از آن بود

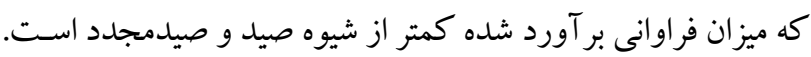

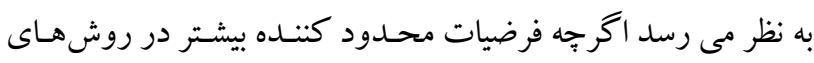

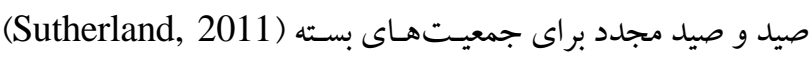

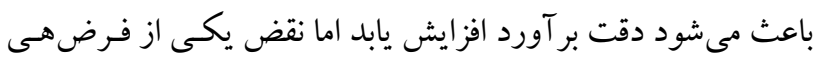

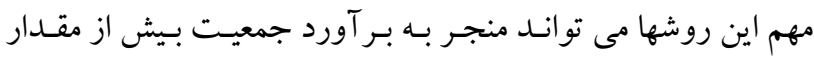
حقيقى شود. يكى از ييشفرض هاى مهم روش هاى فاصلهاى همانــد

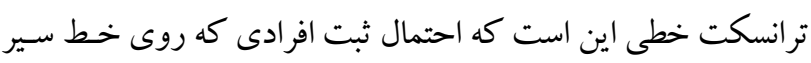

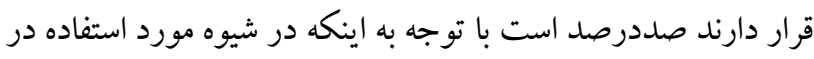

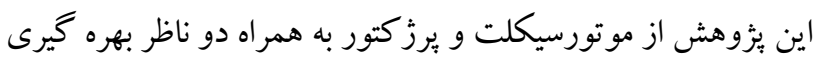

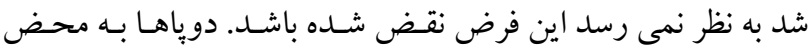

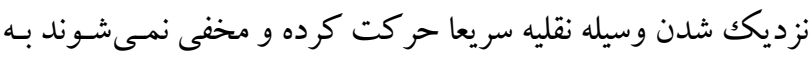

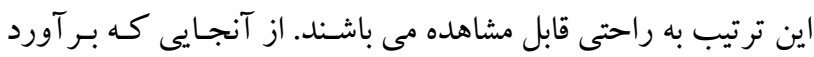

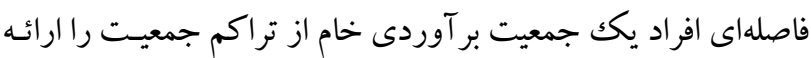

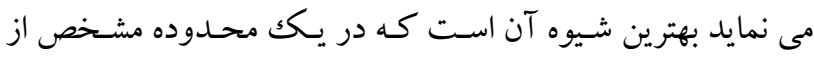
منطقه تحت مطالعه اين شيوه بـه صـورت تصادفى و يـا سيستماتيك

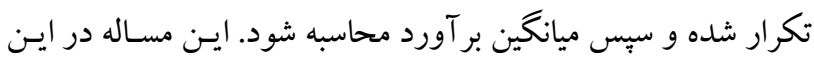

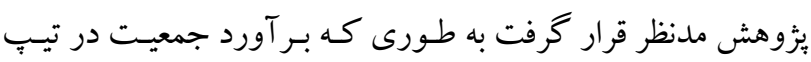

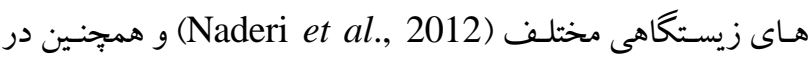

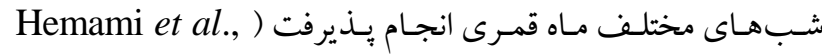

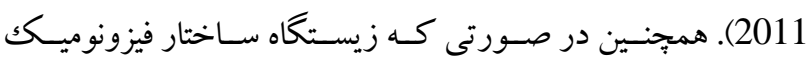
ناهمخونى داشته باشد لازم است تمامى بخش هـا يا اصطلاحا تيبهاى زيستخاهى در مطالعه دخيل باشند.

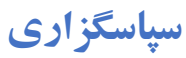

نويسنده از همراهى و همكارى مردم شريف روستاى مير آبـاد بـهـ

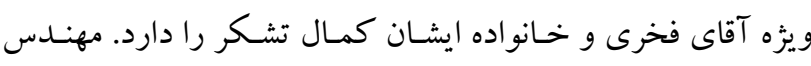

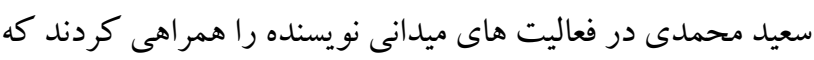
از ايشان تشكر مىشود.

\section{REFERENCES}

Bailey, N.T.J. 1951. On estimating the size of mobile populations from recapture data. - Biometricka 38: 293-306.

Bailey, N.T.J. 1952. Improvements in the interpretation of recapture data. - J. Animal. Ecol. 21: 120-27.
شكل ا نشان داده شده است. همجنين نتايج حاصل از تحليل هـاى انجام شده توسط نرم افزار مذكور در جدول يكك ارائه شده استـ.

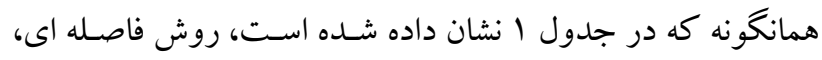

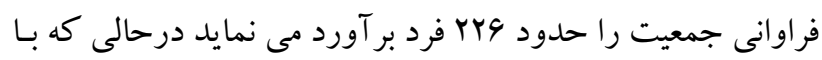

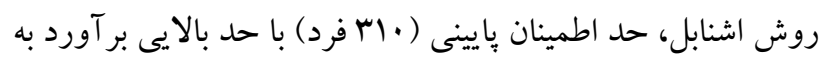

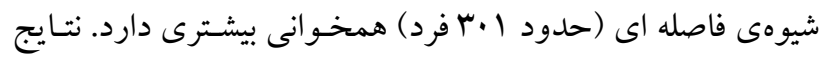

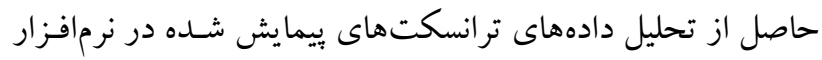

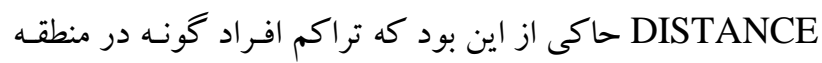

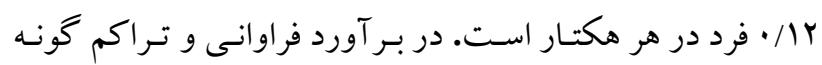
تحت مطالعه به شيوه صيد صيد مجدد، در مجموع در طى مدليـات

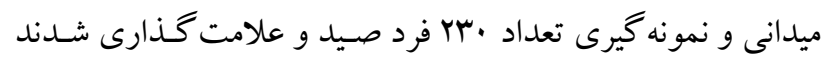

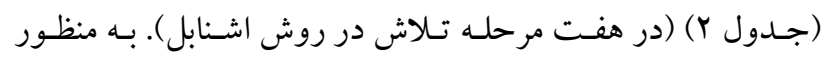

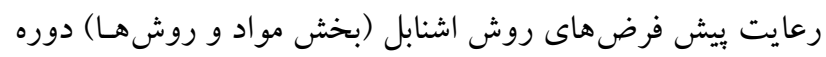

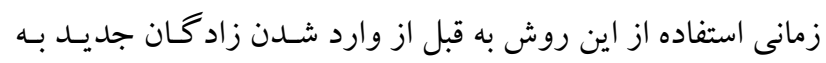

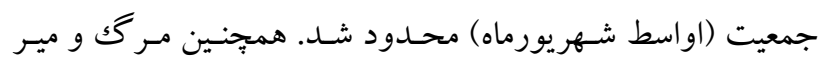

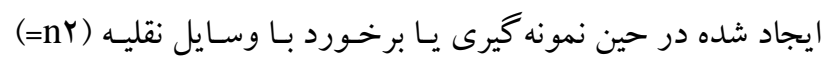

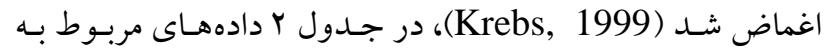
صيد-صيد مجدد ارائه شدهاند. محاسبه تـراكم و فراوانى افراد از

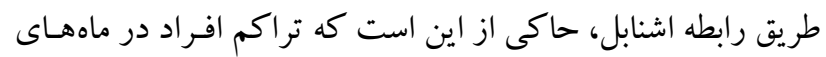

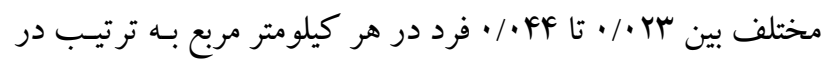

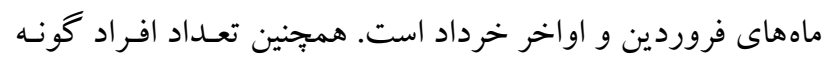

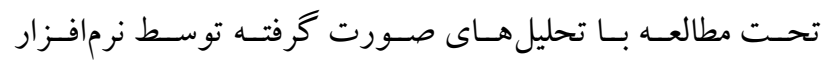
Methodology Ecological

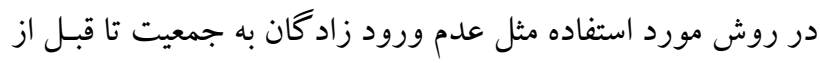

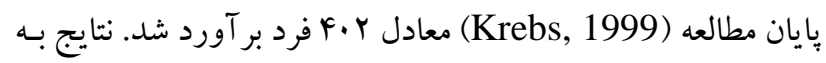

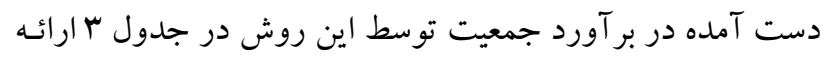

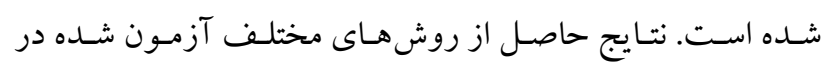

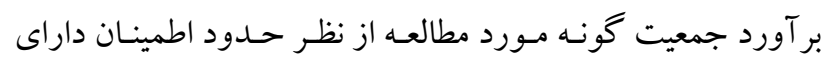

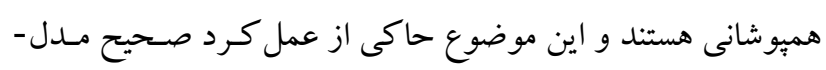

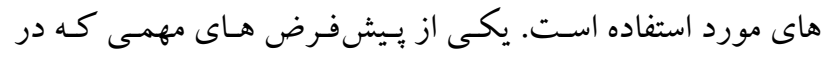

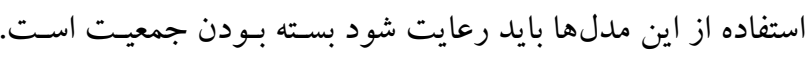

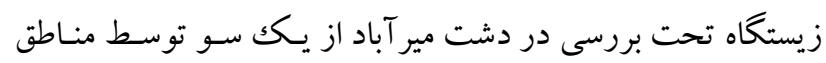

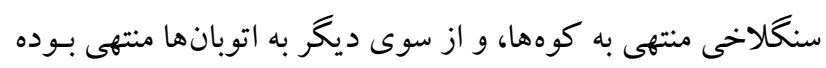

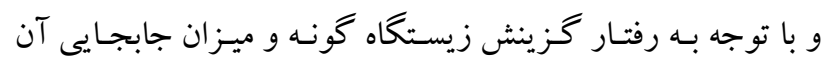

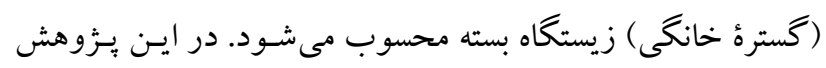


B.C. Ministry of Environment, Lands and Parks. 1998. British Columbia's wildlife species at risk: Western Harvest Mouse Reithrodontomys megalotis.

Çolak, E., Kıvanç, E. and Yiğit, N. 1994. A study on taxonomic status of Allactaga euphratica Thomas, 1881 and Allactaga williamsi Thomas, 1897 (Rodentia: Dipodidae) in Turkey. - Mammalia 58: 591-600.

Darvish, J., Hajjar, T., Moghadam Matin, M., Haddad, F. and Akbary Rad., S. 2008. New species of fiveToed Jerboa (Rodentia: Dipodidae, Allactaginae) from North-East Iran. - J. Sci. 19: 103-109.

Hemami, M.R., Naderi, G.H., Karami, M. and Mohammadi, S. 2011. Nocturnal activity of Iranian Jerboa Allactaga firouzi (Mammalia: Rodentia: Dipodidae). - Mammalia 75: 42-57

Holden, M.E. and Musser, G.G. 2005. Family Dipodidae. - In: Wilson, D.E. \& Reeder, D.A. (eds.), Mammal species of the world: a taxonomic and geographic reference. 3rd ed. 2: 871-893.

Karami, M., Hutterer, R., Benda, P., Siahsarvie, R. and Krystufek, B. 2008. Annotated check-list of mammals of Iran. - Lynx (Praha) 39: 63-102.

Krebs, C.J. 1999. Ecological methodology. 2ed edition. Pearson, p: 620.

Lincoln, F.C. 1930. Calculating waterfowl abundance on the basis of banding returns. - U.S. Dept. Agric. Circ. 118: $1-4$.

MacLeod, J. 1958. The estimation of numbers of mobile insects from low-incidence recapture data. - Trans. Royad Entomol. Soc. London 110: 363-392.

Naderi, G.h., Hemami, M. and Mohammadi, S. 2011. Investigation of habitat preferences of Iranian jerboa (Allactaga firouzi Womochel 1978), - Mammalia 75: 181-184.

Naderi, Gh, Hemami, M. R., Riazi, B. and Alesheikh, A. 2009. Notes on ecological peculiarities of Iranian Jerboa, Allactaga firouzi Womochel, 1978 (Mammalia: Dipodidae). - Zool. Mid. East 47: 21-28.

Parmenter, R.R., Yates, T.L., Anderson, D.R., Burnham, K.P., Dunnum, J.L., Franklin, A.B., Friggens, M.T., Lubow, B.C., Miller, M., Olson, G.S., Parmenter, C.A., Pollard, J., Rexstad, E., Shenk, T.M., Stanley,
T.R. and White, G.C. 2003. Small-mammal density estimation: a field comparison of grid-based vs. webbased density estimators. Ecol. - Monogr. 73: 1-26.

Seber, G.A.F. 1973. The estimation of animal abundance and related parameters. Griffin, London.

Shenbrot, G.I. 1991. Subspecific taxonomy revision of the five-toed jerboas, genus Allactaga (Rodentia, Dipodoidea), of the USSR fauna. Proceedings of the Zoological Institute of the USSR Acaddemy of Science (Leningrad), pp: 42-58.

Shenbrot, G.I. 2009. On the conspecifity of Allactaga hotsoni Thomas, 1920 and Allactaga firouzi Womochel, 1978 (Rodentia: Dipodidae). - Mammalia 73: 241-237.

Shenbrot, G.I., Sokolov, V.E., Heptner, V.G. and Kovalskaya, Yu.M. 1995. Dipodoidea. Moscow: Nauka Publishing House.

Sullivan, T.P. 1997. Sampling methodology for small mammals. - Faculty of Forestry, University of British Columbia, Vancouver, British Columbia, Mimeograph.

Sutherland, W. 2011. Ecological Census Techniques. Cambridge University Press, 431 pp.

Ward, S.J., 2000. The efficacy of nest boxes versus spotlighting for detecting feather tail gliders. - Wil. Res. 27: 75-79.

Wilson, D.J., Mulvey, R.L., Clarke, D.A. and Reardon, J. 2017. Assessing and comparing population densities and indices of skinks under three predator management regimes. - New Zealand J. Ecol. 41: 8497.

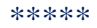

How to cite this article:

Nader, M. 2019. A comparison of linear transect and capture recapture methods results in Iranian Jerboa population density and abundance estimation in Mirabad plains, Shahreza- Nova Biol. Reperta 5: 348-355.

$$
\begin{aligned}
& \text { نادرى، م. Irav. مقايسه شيوهُ ترانسكت خطى و صيد مجدد در برآورد } \\
& \text { فراوانى و تراكم جربواى هاتسونى فيروزى در دشت مير آباد، شهرضا. - يافته - }
\end{aligned}
$$

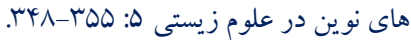

